\title{
Is the shear wave sonographic elastography correlated with pain after breast augmentation with silicone implants an indication of inflammatory activity? A preliminary report
}

\author{
Paweł Rzymski ${ }^{1}$, Mikołaj Kubasik², Michał Gaca ${ }^{3}$, Tomasz Opala ${ }^{1}$ \\ 1Department of Mother's and Child's Health, Poznan University of Medical Science, Gynaecological and Obstetrical University Hospital, \\ Poland \\ 2Individual Plastic Surgery Practice, Poznań-Zakrzewo, Poland \\ ${ }^{3}$ Department of Anaesthesiology in Gynaecology and Obstetrics, Poznan University of Medical Science, Gynaecologic and Obstetrical \\ University Hospital, Poland
}

Videosurgery and Other Miniinvasive Techniques 2011; 6 (4): 217-225 DOI: $10.5114 /$ wiitm.2011.26255

\begin{abstract}
Introduction: Formation of a capsule is a natural inflammatory response to a foreign body such as a breast implant. Breast capsular contracture is the most severe complication of implant surgery.

Aim: To evaluate breast tissues and the periprosthetic reaction with sonoelastography.

Material and methods: Nineteen patients aged 20-41 underwent breast augmentation with silicone-filled implants. Their 38 breasts were evaluated before surgery, and 7 and 14 days after surgery. Whole breast stiffness was measured by applanation tonometry. Patients underwent shear wave elastography and Young's moduli of breast tissues and the periprosthetic capsule were estimated. During surgery patients underwent standard anaesthesia and were released home 2 days later after removal of drainage. Each day, patients completed the pain visual analogue scale questionnaire separately for left and right breasts.

Results: Applanation tonometry did not correlate with any parameter. In shear wave elastography we observed statistically significant changes in elasticity of all breast tissues with the highest values on day 7 after surgery and decreasing on day 14. The correlations between pain and capsule elasticity in lower quadrants measured were significant between days 4 and 10, whereas correlations of pain with applanation tonometry were insignificant. Glandular tissue elasticity in lower quadrants did not correlate with pain, whereas in upper quadrants there was a significant correlation on days 6-10. Fatty tissue, muscle and thoracic fascia elasticity did not correlate with breast pain. Breast implant volume correlated with pain only shortly after surgery, but did not correlate with any sonoelastographic parameters. Conclusions: Breast pain correlates strongly with periprosthetic stiffness in elastography 4 to 10 days after breast augmentation, suggesting the possible role of an inflammatory reaction.
\end{abstract}

Key words: breast augmentation, implant, ultrasound, elastography, capsular contracture.

\section{Introduction}

Breast capsular contracture is an unwanted complication of implant surgery, resulting in peri-implant fibrosis and capsular formation beyond the normal state. But formation of a capsule is a natural inflammatory response to a foreign body such as a breast implant [1]. When it occurs in an excessive manner, 
the surrounding tissue leads to contracture, distortion, hardness and pain. Periprosthetic breast capsules are composed of dense connective tissue containing dense collagen fibres, reticulum and an inner surface with fibrocytes and histiocytes which form an epithelium-like layer. The capsule usually has typically dense fibrocollagenous or fibrovascular connective tissue containing foreign-body giant cells or granulomas or a local immune response. The immune inflammatory response, whether bacterial or as a reaction to a foreign body, starts during wound healing [1-3]. The capsule adjacent to smooth-surfaced implants is surrounded by mesothelial-like cells containing no lining and is avascular with well-oriented collagen fibres. The textured surface of the implant results in epithelial lining and multidirectional fibre orientation in the surrounding capsule $[1,4,5]$. The synovial-like metaplasia and villous hyperplasia decrease with time after breast augmentation surgery. The density of the collagenous capsule decreases in textured implants with time, but increases in smooth-surfaced ones. The foreign body granulomatous reaction increases with time. A textured shell of implants compared to smooth ones decreases fibroblast proliferation and increases the inflammatory response, which finally result in delay of collagen deposition $[4,5]$.

Acute pain after breast augmentation lasts days after surgery and within months could persist as chronic pain in some patients. Pain after implant insertion is relatively frequent (53\%) compared with mastectomy or breast reconstruction (30\%). About $20 \%$ of patients after breast augmentation could require pain medication [6].

Various factors are involved in capsule formation and are similar to those provoking disorders such as liver sclerosis, glomerulonephritis and scleroderma. Cytokines such as transforming growth factor $\beta$ (TGF- $\beta$ ) and connective tissue growth factor (CTGF) are considered $[2,3]$

Although most would consider the degree of capsular thickness to be correlated with severity of capsular contracture, this has never been definitively proved. As up to $30 \%$ of patients with Baker III/IV contracture (abnormal appearance of breast, firmness, eventual hardness and pain) could require secondary surgery, early detection of excessive capsule formation would be of clinical importance [1], especially because there are newly researched agents raising hopes to decrease capsule formation, such as angiotensin-converting enzyme inhibitors, 2-mercaptoethane sulfonate, leukotriene inhibitors or TGF- $\beta$ inhibitors [1, 3]. Anther method to treat or prevent contractures is iE external ultrasound [7].

The aim of our study was to evaluate in the perioperative period all breast tissues and periprosthetic reactions with the newly developed imaging technique of sonoelastography.

\section{Material and methods \\ Study protocol}

Between September 2010 and March 2011, 19 patients aged 20-41 underwent breast augmentation performed by a senior plastic surgeon with siliconefilled texturized implants. Before surgery they underwent breast ultrasound examination and real-time shear wave sonoelastography. This method enables one to measure tissue stiffness (Young's moduli) presented in a colour-coded manner. We set the region of interest to reach subcutaneous fat tissue and muscle. Fat and glandular tissue, thoracic fascia and muscle were measured by elastography in 4 quadrants (if appropriate) [8, 9]. After elastography we examined the breast stiffness by applanation tonometry, as previously described in the literature. The organ's pressure is calculated according to the formula $P=F / A$, where $A$ stands for contact area of a $20.3 \mathrm{~cm}$ diameter disc weighing $213 \mathrm{~g}$ [10].

A surgeon with 10 years of experience in breast augmentation performed 19 subsequent bilateral submuscular augmentation mammaplasties with siliconefilled texturized implants (Natrelle, Allergan, United Kingdom). All patients were admitted fasting to the clinic and received a prophylactic intravenous antibiotic (1.5 g cefuroxime). The procedure started with breast fold incision after saline and adrenalin injection. Blunt dissection of glandular fascia at the bottom and muscle at the top was performed with the dual plane technique previously described [11]. Patients received symmetrical or asymmetrical implants when needed; their volume ranged from 180 to $545 \mathrm{cc}$. After insertion of implants, drainage around the implants was left for $48 \mathrm{~h}$. Sixty min before surgery, patients received midazolam $0.1-0.2 \mathrm{mg} / \mathrm{kg}$, and $2 \mathrm{~min}$ before induction, remifentanil $1 \mu \mathrm{g} / \mathrm{kg}$ intravenously followed by 1.5-2.0 $\mathrm{mg} / \mathrm{kg}$ of propofol and mivacurium $0.15 \mathrm{mg} / \mathrm{kg}$. Patients were intubated and propofol infusion was applied with Roberts formula $(1.5 \mathrm{mg} / \mathrm{kg}$ propofol loading dose followed by $10 \mathrm{mg} / \mathrm{kg} / \mathrm{h}$ infusion successively reduced). Patients were ventilated with oxygen/air 
$\left(\mathrm{FiO}_{2}\right.$ 0.35). Propofol and remifentanil were repeated if necessary. Standard anaesthesia monitoring was used. In pre-emptive anaesthesia, $1 \mathrm{~g}$ intravenous acetaminophen was used. The residual action of analgesics decreases the postoperative pain and in the majority of patients non-steroid anti-inflammatory drugs administered orally are sufficient to control pain [12]. After drainage was removed, patients were released from the clinic. They controlled eventual pain by administration of $75 \mathrm{mg}$ diclophenac sodium orally twice a day. Patients were asked to fill in the questionnaire separately for the left and right breast, indicating pain on a $100 \mathrm{~mm}$ visual analogue scale (VAS) before taking any medication to control pain. They registered pain every day to follow up pain regression until 14 days after the surgical procedure.

In several studies in animal models, early immunological response, inflammation and fibrotic tissue formation were observed in first 4 weeks after surgery $[2,4]$. Based on the above-mentioned reason, early examinations for breast contractures, complications and pain not correlated with surgical treatment were performed 7 and 14 days after breast augmentation. We examined the patients clinically and by ultrasound. We evaluated capsular formation (thickness), eventual fluid, hematomas, etc. Applanation tonometry was also performed as well as sonoelastography, as described above. The only modification was additional elasticity measurement of an early capsule that presented in harmonic imaging as a separate layer above the breast implant [13]. The capsular elasticity was measured in 4 quadrants.

\section{Data analysis}

Data are presented as means \pm standard deviation (SD). Area under receiver operating characteristic curve (AROC) was calculated with 95\% confidence interval (CI). Repeated measurements were analysed with Friedman's test. Correlations were estimated by Spearman's test. Values of $p$ less than 0.05 were considered significant; otherwise the abbreviation NS was used to indicate an insignificant p level. SigmaStat v3.1 (Systat Inc) and Medcalc 8.0 (Schoonjans, Belgium) were used for statistical calculations. The study was approved by the local university bioethics committee (approval no. 93/11).

\section{Results}

We did not observe any problem with shear wave penetration in all tissues including the surface of the prosthesis. Tissue stiffness of tissues measured by applanation tonometry before surgery, and 7 and 14 days after breast augmentation are presented in Table I. We observed statistically significant changes in elasticity of all breast tissues in elastography examination. The values before surgery were low and increased on day 7 after surgery, with a slight decrease on day 14 . The elastographic scans 7 and 14 days after surgery in the same patient and quadrant are presented in Figures 1 and 2. Mean values of all breast tissue changes and capsular stiffness changes are presented in Table I. Patients reported pain using the VAS and mean values of their follow-up are presented in Figure 3. We wanted to check if pain dynamic changes are followed by tonometry or elastography. We analysed all days from the $1^{\text {st }}$ to $14^{\text {th }}$ after surgery, but made sonoelastographic measurements on days 7 and 14 because we supposed that pain is a dynamic process and should also correlate in close days. The correlations between VAS pain and capsule elasticity in lower quadrants measured by elastography were significant between days 4 and 10, whereas correlations of VAS pain with applanation tonometry were insignificant (Table II, Figure 4). Interestingly, glandular tissue elasticity in lower quadrants did not correlate with VAS pain, whereas in upper quadrants where glandular tissue concentration is higher, the correlation was significant during days 6-10. Fatty tissue elasticity did not correlate with breast pain (Table III). Because of muscle pocket preparation we hoped to find a strong correlation between muscle and thoracic fascia tissue elasticity and VAS pain, but except for day 6, they were insignificant. Breast implant volume correlated with pain only shortly after surgery (first 2 days; data presented in Table IV). Additionally, breast implant volume did not correlate with applanation tonometry or any of the sonoelastographic parameters. We tried to find factors predicting higher breast pain after augmentation by receiver operating characteristic (ROC) analysis. The strongest predictors of pain more than $30 \mathrm{~mm}$ on the VAS were periprosthetic elasticity measured at day 7 and fatty tissue elasticity in the outer quadrant before surgery. Data are presented in Table $\mathrm{V}$ and Figure 5 .

\section{Discussion}

The pathomechanism of periprosthetic breast capsule formation has not been definitively deter- 
Table I. Mean values of breast tissues before surgery and on days 7 and 14 with additional capsule elasticity measurements

\begin{tabular}{|lcccc|}
\hline Parameter & Before surgery & Day 7 after surgery & Day 14 after surgery & Friedman test $(p)$ \\
\hline Tonometry [N/cm²] & $631 \pm 139$ & $1009 \pm 239$ & $987 \pm 230$ & $<0.001$ \\
\hline Glandular tissue (upper quadrant) $[\mathrm{kPa}]$ & $8.7 \pm 3.3$ & $12.6 \pm 4.4$ & $12.3 \pm 6.6$ & 0.002 \\
\hline Fat tissue (upper quadrant) [kPa] & $9.4 \pm 5.2$ & $12.2 \pm 5.1$ & $10.4 \pm 5.2$ & 0.008 \\
\hline Fascia (upper quadrant) [kPa] & $9.8 \pm 5.4$ & $13.8 \pm 5.5$ & $12.0 \pm 5.4$ & $<0.001$ \\
\hline Muscle (upper quadrant) [kPa] & $11.6 \pm 10.2$ & $15.1 \pm 6.1$ & $15.1 \pm 7.2$ & 0.019 \\
\hline Glandular tissue (lower quadrant) $[\mathrm{kPa}]$ & $4.7 \pm 2.3$ & $10.9 \pm 6.4$ & $9.4 \pm 5.3$ & 0.003 \\
\hline Fat tissue (lower quadrant) [kPa] & $6.0 \pm 2.8$ & $10.0 \pm 6.3$ & $11.9 \pm 5.0$ & $<0.001$ \\
\hline Glandular tissue (outer quadrant) $[\mathrm{kPa}]$ & $6.9 \pm 4.3$ & $14.0 \pm 7.1$ & $10.8 \pm 4.6$ & $<0.001$ \\
\hline Fat tissue (outer quadrant) [kPa] & $6.7 \pm 4.8$ & $13.4 \pm 7.1$ & $18.2 \pm 6.8$ & $0.029^{*}$ \\
\hline Capsule elasticity (upper quadrant) $[\mathrm{kPa}]$ & $\mathrm{n} / \mathrm{a}$ & $20.6 \pm 5.8$ & $20.1 \pm 6.0$ & $0.018^{*}$ \\
\hline Capsule elasticity (lower quadrant) $[\mathrm{kPa}]$ & $\mathrm{n} / \mathrm{a}$ & $23.0 \pm 8.3$ & $22.1 \pm 6.9$ & $0.005^{*}$ \\
\hline Capsule elasticity (outer quadrant) $[\mathrm{kPa}]$ & $\mathrm{n} / \mathrm{a}$ & $26.1 \pm 8.8$ & $21.5 \pm 6.3$ & $<0.001^{*}$ \\
\hline Capsule elasticity (inner quadrant) $[\mathrm{kPa}]$ & $\mathrm{n} / \mathrm{a}$ & $27.7 \pm 9.2$ & & \\
\hline
\end{tabular}

${ }^{*}$ Wilcoxon test, n/a

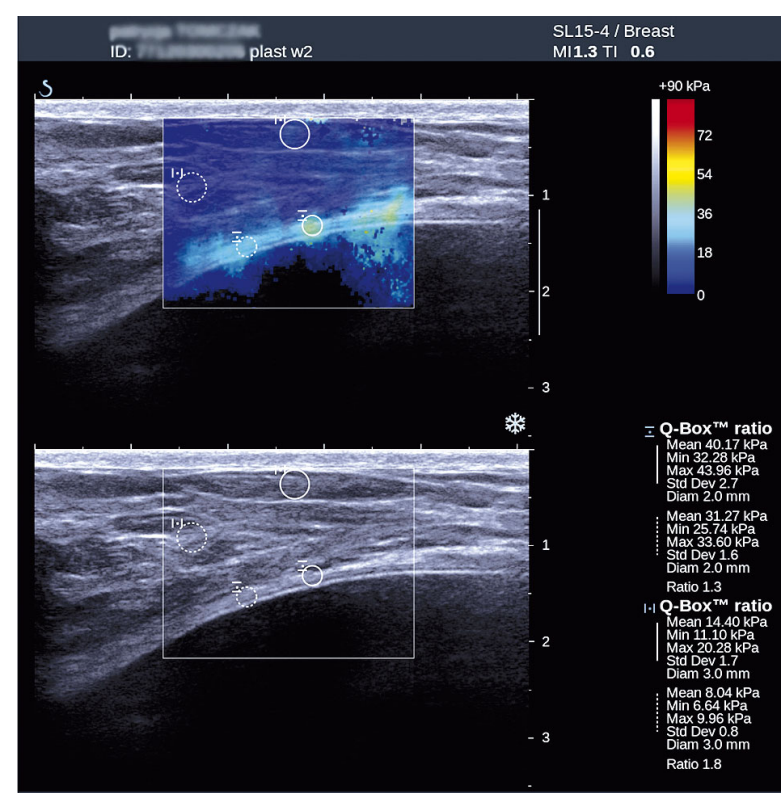

Figure 1. Sonoelastographic scan and measurements 7 days after surgery

mined. But all theories underpin the pivotal role of an inflammatory reaction, which leads to fibrosis [1]. In some studies tissue factors present in the tissue

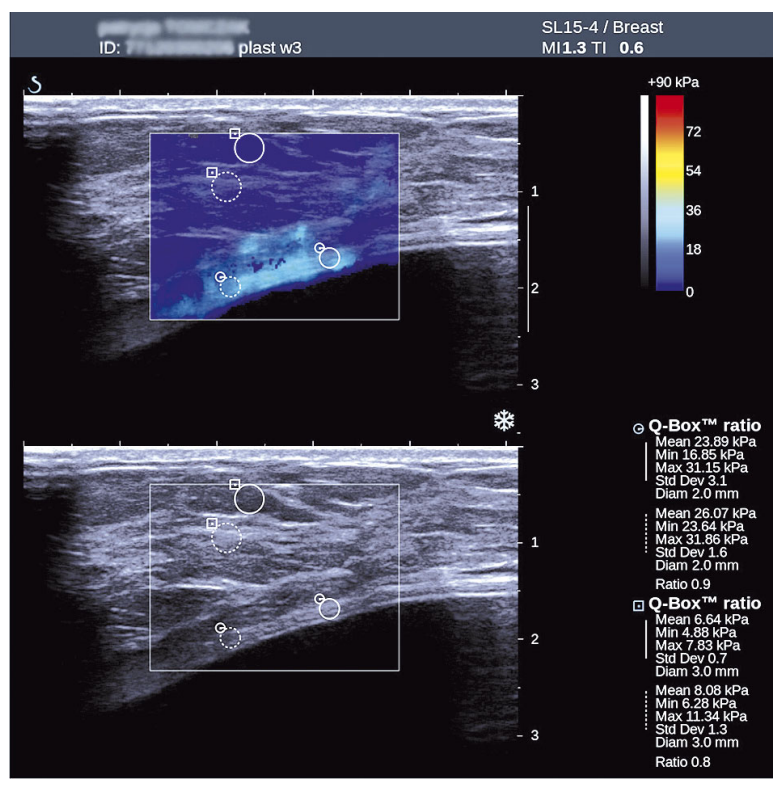

Figure 2. The same patient as in Figure 1 examined 14 days after surgery. Periprosthetic stiffness decreased

response were measured in animal models. Levels were higher starting from the $7^{\text {th }}$ day and were similar or higher during the next 3 weeks. But such stud- 
ies are not possible in humans, because capsules were evaluated pathologically in their early formation by resection [2]. On the other hand, excessive early capsular formation could lead to late complications such as significant contracture. There are several agents which have been studied to inhibit capsular formation, such as TGF- $\beta$ antisense oligonucleotide and leukotriene inhibitors; all are potentially useful in clinical practice. They reduce capsular thickness in longer follow-up [3]. But the method of early prediction of excessive capsular formation is missing. In several studies levels of TGF- $\beta$ failed in humans to predict capsular contracture [2]. We tried to evaluate a novel, non-invasive method and our initial results in short-term study are promising.

The aetiology of pain following augmentation breast surgery is uncertain. There is evidence that trauma to the ribs, bleeding into dissected pockets or trauma to the breast itself may be responsible for this sensation. Some authors suggest that duration of the surgical procedure and inflammation may be of importance here [14]. The pain after augmentation surgery may originate from direct brachial plexus compression or referred pain from implants. The long thoracic nerve has also been reported to be damaged, leading to chronic pain. The above-described chronic pain due to focal nerve injuries originates from short patches of demyelination, neuroma or

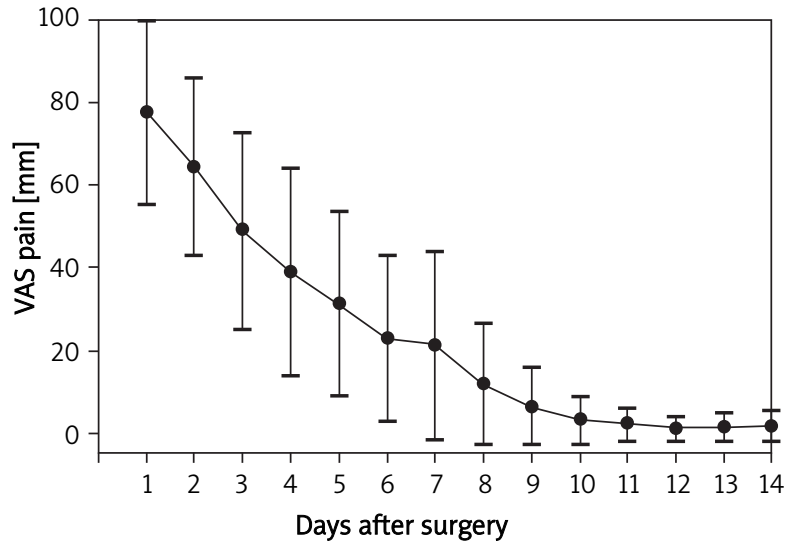

Figure 3. Follow-up of breast pain estimated by VAS on days 1-14 after breast augmentation

microneuroma. But more typical for breast implants is capsule formation, which leads to nerve compression. Capsular formation under the pectoralis major muscle in submuscular placed implants would more likely result in compression and ischaemia of nerves arising from the brachial plexus. This explains the higher incidence of pain in the case of submuscular location of the implant [6]. But also different sites are suggested to be involved in the pain process following breast augmentation mammoplasty. They include for example sternal pain, which is better controlled by narcotics. Also blunt and sharp dissection seems

Table II. Breast pain correlates with capsular elasticity mainly in lower quadrants, but not with applanation tonometry

\begin{tabular}{|lcccc|}
\hline $\begin{array}{l}\text { Mean pain } \\
\text { VAS score: } \\
\text { day after surgery }\end{array}$ & $\begin{array}{c}\text { Correlation of } \\
\text { VAS score } \\
\text { with tonometry* }\end{array}$ & $\begin{array}{c}\text { Correlation of } \\
\text { capsular elasticity } \\
\text { (lower quadrants) } \\
\text { with VAS score** }\end{array}$ & $\begin{array}{c}\text { Correlation of } \\
\text { capsular elasticity } \\
\text { (upper quadrants) } \\
\text { with VAS score* }\end{array}$ & $\begin{array}{c}\text { Correlation of } \\
\text { capsular elasticity } \\
\text { (inner-outer quadrants) } \\
\text { with VAS score* }\end{array}$ \\
\hline $1-3$ & NS & NS & NS & NS \\
\hline 4 & NS & Rs $=0.42, p=0.03, p<0.001$ & NS & NS \\
\hline 5 & NS & Rs $=0.59, p<0.001$ & NS & NS \\
\hline 6 & NS & Rs $=0.45, p=0.01$ & NS & NS \\
\hline 7 & NS & Rs $=0.55, p=0.001$ & RS $=0.39, p=0.02$ & NS \\
\hline 8 & NS & Rs $=0.54, p=0.001$ & NS & NS \\
\hline 9 & NS & Rs $=0.47, p=0.006$ & NS & NS \\
\hline 10 & NS & NS & NS & NS \\
\hline $11-14$ & NS & NS & NS & NS \\
\hline
\end{tabular}

${ }^{*}$ Change in applanation tonometry expressed as \% change between preoperative tonometry and day 7 after surgery, ${ }^{\star *}$ As above 
not to influence pain after breast augmentation surgery [14]. In our study we examined acute pain and its dynamics (resolution) within the first 2 weeks. We found a strong positive correlation between periprosthetic stiffness and pain on the fourth to $10^{\text {th }}$ day

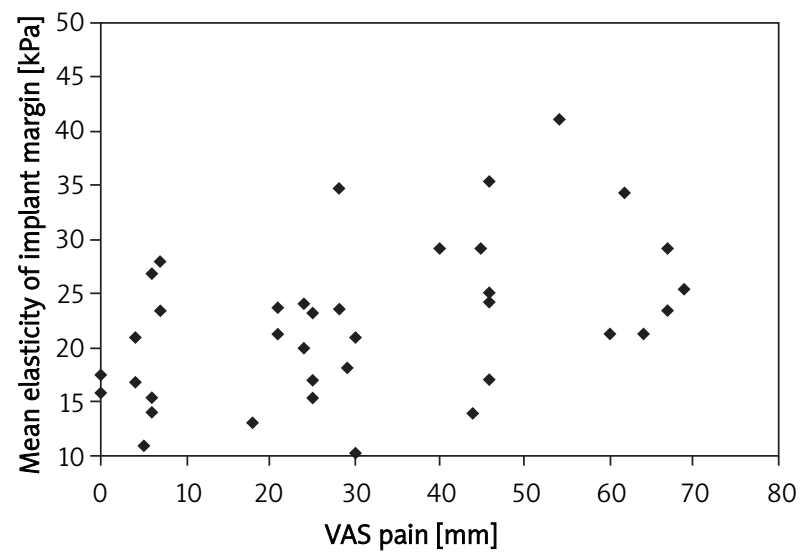

Figure 4. Correlation between mean elasticity measured by sonoelastography at 7 th day after surgery and VAS pain evaluation after breast augmentation surgery. This finding was limited to the lower quadrant, where the incision is made, the major part of the implant is placed and traumatisation of tissues is high. The submuscular placement of the implant and transsection of its inferior border leads to significant pain in the postoperative period [15]. We could hypothesize that it reflects the activity of the inflammatory process on the surface of the implant, and thus the early capsule formation or at least its velocity. Endings of traumatized nerves from the pectoralis major muscle and subglandular fascia with their nociceptors are highly activated when inflammation is greater. Parallel inflammation leads to more emphasized capsule formation, and greater thickness and stiffness [2, 4]. After surgery, inflammatory pain and subsequent ongoing nociceptive signals from peripheral nerve injuries induce a central sensation. This could be decreased by for example injection of the pectoralis muscle with bupivacaine with epinephrine [15]. It could persist as chronic pain 3-12 months up to decades after the

Table III. Glandular and fat tissue elasticity measured at 7th day after surgery correlates in upper quadrant with breast pain

\begin{tabular}{|lcccc|}
\hline $\begin{array}{l}\text { Mean pain } \\
\text { VAS score: } \\
\text { day after surgery }\end{array}$ & $\begin{array}{c}\text { Correlation of } \\
\text { glandular tissue elasticity } \\
\text { (lower quadrants) } \\
\text { with VAS score }\end{array}$ & $\begin{array}{c}\text { Correlation of } \\
\text { glandular tissue elasticity } \\
\text { (upper quadrants) } \\
\text { with VAS score }\end{array}$ & $\begin{array}{c}\text { Correlation of } \\
\text { glandular tissue elasticity } \\
\text { (inner-outer quadrants) } \\
\text { with VAS score }\end{array}$ & $\begin{array}{c}\text { Correlation of } \\
\text { fat tissue elasticity } \\
\text { (any quadrant) } \\
\text { with VAS score }\end{array}$ \\
\hline $1-5$ & NS & NS & NS & NS \\
\hline 6 & NS & Rs $=0.33, p=0.03$ & NS & NS \\
\hline 7 & NS & Rs $=0.32, p=0.03$ & NS & NS \\
\hline 8 & NS & Rs $=0.33, p=0.03$ & NS & NS \\
\hline 9 & NS & Rs $=0.39, p=0.01$ & NS & NS \\
\hline 10 & NS & Rs $=0.35, p=0.02$ & NS & NS \\
\hline $11-14$ & NS & &
\end{tabular}

Table IV. Muscle and thoracic fascia tissue elasticity (7th day after surgery) and breast pain

\begin{tabular}{|lccc|}
\hline $\begin{array}{l}\text { Mean pain } \\
\begin{array}{l}\text { VAS score: } \\
\text { day after surgery }\end{array}\end{array}$ & $\begin{array}{c}\text { Correlation of muscle } \\
\text { tissue elasticity (upper quadrant) } \\
\text { with VAS score }\end{array}$ & $\begin{array}{c}\text { Correlation of } \\
\text { fascia elasticity (upper quadrant) } \\
\text { with VAS score }\end{array}$ & Implant volume [ml] \\
\hline $1-5$ & NS & NS & Rs $=-0.31, p=0.05$ \\
\hline 6 & RS $=0.33, p=0.04$ & NS & Rs $=-0.36, p=0.02$ \\
\hline $7-14$ & NS & NS & NS \\
\hline
\end{tabular}


Table V. The power of elasticity estimation in predicting pain more than $30 / 100$ on VAS at $5^{\text {th }}$ day after surgery

\begin{tabular}{|c|c|c|}
\hline Change between day 7 and 0 in: & AROC & $95 \% \mathrm{Cl}$ \\
\hline Tonometry [N/cm²] & 0.56 & $0.39-0.72$ \\
\hline Glandular elasticity in upper quadrant (\%) & 0.62 & $0.48-0.77$ \\
\hline Fat tissue elasticity in upper quadrant (\%) & 0.53 & $0.36-0.69$ \\
\hline $\begin{array}{l}\text { Thoracic fascia elasticity in upper } \\
\text { quadrant (\%) }\end{array}$ & 0.53 & $0.37-0.69$ \\
\hline Muscle elasticity in upper quadrant (\%) & 0.60 & $0.42-0.75$ \\
\hline Glandular elasticity in lower quadrant (\%) & 0.62 & $0.45-0.77$ \\
\hline Fat tissue elasticity in lower quadrant (\%) & 0.52 & $0.35-0.58$ \\
\hline Glandular elasticity in outer quadrant (\%) & 0.52 & $0.35-0.57$ \\
\hline Fat tissue elasticity in outer quadrant (\%) & 0.57 & $0.40-0.73$ \\
\hline Preoperative measurements & AROC & $95 \% \mathrm{Cl}$ \\
\hline Tonometry $\left[\mathrm{N} / \mathrm{cm}^{2}\right]$ & 0.57 & $0.40-0.72$ \\
\hline Glandular elasticity in upper quadrant $[\mathrm{kPa}]$ & 0.49 & $0.33-0.63$ \\
\hline Fat tissue elasticity in upper quadrant [KPa] & 0.49 & $0.33-0.61$ \\
\hline $\begin{array}{l}\text { Thoracic fascia elasticity in upper } \\
\text { quadrant }[\mathrm{kPa}]\end{array}$ & 0.53 & $0.36-0.69$ \\
\hline Muscle elasticity in upper quadrant [kPa] & 0.57 & $0.40-0.73$ \\
\hline Glandular elasticity in lower quadrant [KPa] & 0.53 & $0.36-0.62$ \\
\hline Fat tissue elasticity in lower quadrant [kPa] & 0.59 & $0.41-0.74$ \\
\hline Glandular elasticity in outer quadrant $[\mathrm{kPa}]$ & 0.63 & $0.46-0.78$ \\
\hline Fat tissue elasticity in outer quadrant [kPa] & 0.74 & $0.57-0.89$ \\
\hline Capsule elasticity at 7 th day & AROC & $95 \% \mathrm{Cl}$ \\
\hline Capsule elasticity in & 0.72 & $0.55-0.85$ \\
\hline
\end{tabular}

procedure [16]. Several agents, including parecoxib and methylprednisolone, may decrease acute postoperative pain in breast surgery. But acute pain is potentially decreased until the $5^{\text {th }}$ day after surgery; there were no differences in subsequent days and up to a year compared to placebo [17]. In our study pain correlated with capsule stiffness later, suggesting a different origin. In the first 3 days it did not correlate with capsular periprosthetic stiffness and it is more likely to be caused by surgical trauma itself. In the next 7 days it correlated strongly; we could hypothesize that the cause is more likely to be

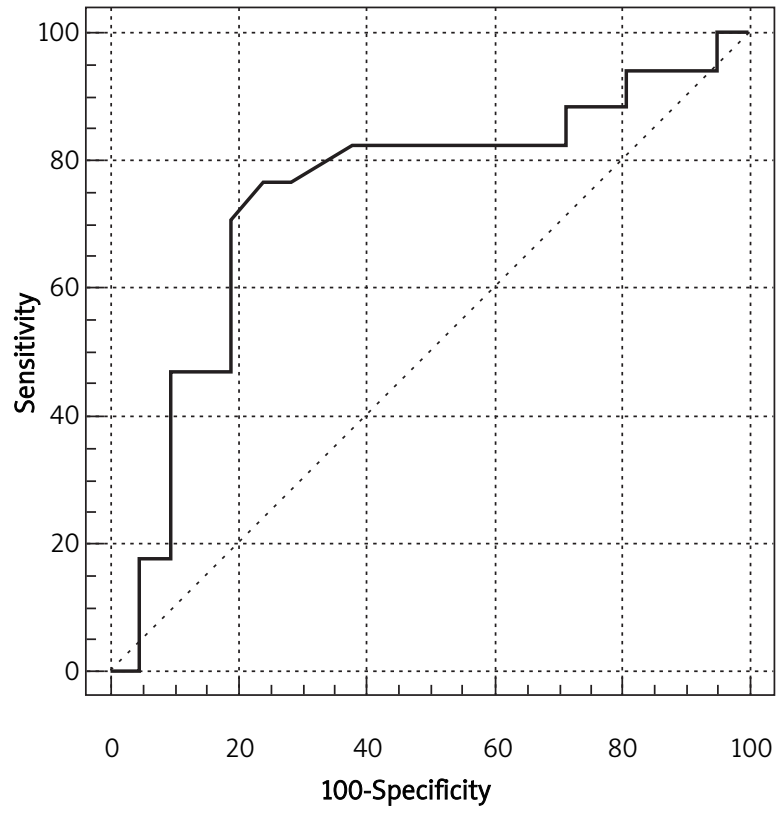

Figure 5. ROC analysis: preoperative fat tissue elasticity in outer quadrant in predicting pain greater than VAS 30/100 on $5^{\text {th }}$ day after breast implant insertion

inflammatory. In the presence of inflammatory agents, traumatized nerves are stimulated more strongly in patients where a more intense response takes place. It has been suggested that the intercostal nerve could be responsible for postoperative pain, but its preoperative blocks do not decrease postoperative pain [14]. The pain in our study decreased over time, but the mean value after 14 days was $1.5 \mathrm{~mm}$ on the VAS. In other studies pain evaluated 6 weeks after surgery or 1 year was also persistent in some patients. A relatively high VAS score in the $1^{\text {st }}$ days after surgery was also reported in the literature and patients required sometimes up to 8 days of opioid agents to decrease it. Especially on day 7 after surgery the mean VAS score in our study and others are almost identical. In our earlier study with different breast surgery up to $70 \%$ of patients reported pain of more than $30 \mathrm{~mm}$ on the VAS scale and $23.3 \%$ more than $50 \mathrm{~mm}$ within the $1^{\text {st }}$ day [18]. But early pain in the first 2 days was better controlled in a study by Pacik et al., where bupivacaine catheter instillation was performed (mean VAS scores 50 and $45 \mathrm{~mm}$ respectively) [14]. In another study acute pain within the first 4 weeks after surgery was also reported in $42 \%$ of patients [16]. In our 
previous study in healthy women we analysed breast pain measured on the same VAS scale and elasticity of glandular and fat tissue. There was no correlation between them, but we found a weak negative correlation between glandular or fat tissue heterogeneity and elasticity [8]. In this study also an interesting correlation between glandular elasticity in upper quadrants and pain several days after surgery was noted. It could represent the highest density and amount of glandular tissue in the upper-outer quadrant, and elastographic differences have also been found in earlier studies [8, 9]. Some authors also suggest that this sudden stretch of breast tissues combined with dissection trauma are most important in pain origin after augmentation surgery [14]. The influence of sex hormones and the menstrual cycle in our previous study did not significantly affect breast elasticity of glandular and fat tissue and could be omitted in interpretation of these results $[9,19]$.

The stiffness of breasts observed in applanation tonometry reached the highest values 7 days after surgery and decreased on the $14^{\text {th }}$ day. No correlation between breast tonometry and pain was observed, suggesting that pain has no tissue-stretching origin. But also almost all tissues increased their stiffness in elastography after augmentation, with a tendency to decrease 14 days after surgery, but only periprosthetic elasticity correlated with pain. It has been reported that capsular contracture was associated higher risk of pain reported, and histological findings of inflammation would be a linking bridge between them [16]. Another finding of our study was also that glandular elasticity measured at the $7^{\text {th }}$ day after surgery correlated with pain, but in the upper quadrant only. We could hypothesize that it represents mastodynia, which is preferably present in the upper-outer quadrant due to higher glandular tissue volume. The correlation between implant volume and VAS score in the first 2 days after breast augmentation was another interesting relationship in our material. Starting from the $3^{\text {rd }}$ day, no correlation was observed. In other studies, no correlations between these parameters were also observed [14].

Acute inflammation as the response to a foreign body prolongs into chronic inflammation as the repair process [1]. Indirectly it was also proven that the inflammation is active early after surgery [3]. In the initial phase of inflammation $24 \mathrm{~h}$ after injury, different cells enter the site of injury and vasoactive and chemotactic agents are released. After a few days the remodelling process starts and lasts for a few weeks [20]. It was also proved that the initial capsule thickness, vascularity and parallel alignment of collagen fibres measured 30 days after implant surgery does not increase in the following 2 months. That is why we focused on early imaging of augmented breasts, when all crucial pathophysiological processes take place [7]. In another study it was histologically proven that granulation, vessel proliferation, chronic inflammation, capsule fibrosis and fibroblast cellularity were together and separately inhibited by AlloDerm submuscular insertion in breast reconstruction. The acellular cadaveric dermis helps to cover the muscle and potentially decreases postoperative discomfort. The inhibition of inflammation results in a different capsular structure in areas of bare pectoralis muscle and where AlloDerm (Regenerative Tissue Matrix) is present [1].

A limitation of this study is that we could not directly measure the inflammatory process in the periprosthetic space, which would be the evidence of observed correlations. The second limitation is that the long-term follow-up is still in progress, and we plan to control all patients 12 and 24 months after primary surgery, but capsule formation sometimes lasts much longer $[1,4]$. But from a clinical point of view, very early selection of patients who will develop excessive capsule formation is of importance. To our knowledge this is the first study in the literature analysing the potential role of sonoelastography in breast augmentation surgery. We also observed 2 cases with capsular contractures visible in elastographic examination which showed a decrease in stiffness after secondary surgery (capsulectomy and capsulotomy) [21]. Thus this should be considered a pilot study, and we hope it not only adds to the knowledge of capsule formation, but raises hopes to predict this complication and at least partially prevent it as early as possible.

\section{Conclusions}

1. Shear wave elastography, being capable of estimating tissue stiffness after breast augmentation procedures, offers new possibilities of postoperative follow-up in patients undergoing breast augmentation with implants.

2. The tissue stiffness measured in elastography correlates strongly with breast pain between the $4^{\text {th }}$ and $10^{\text {th }}$ day after breast augmentation, indicating the possible role of an early inflammatory reaction. 


\section{References}

1. Basu BC, Leong M, Hicks MJ. Acellular cadaveric dermis decreases the inflammatory response in capsule formation in reconstructive breast surgery. Plast Reconstr Surg 2010; 6: 1842-7.

2. Mazaheri MK, Schultz GS, Blalock TD, et al. Role of connective tissue growth factor in breast implant elastomer capsular formation. Ann Plast Surg 2003; 3: 263-8.

3. Reid RR, Greve SD, Casas LA. The effect of zafirlukast (Acculate) on early capsular contracture in the primary augmentation patient: a pilot study. Aesthetic Surg I 2005; 25: 26-30.

4. Wyatt LE, Sinow JD, Wollman JS, et al. The influence of time on human breast capsule histology: smooth and textured siliconesurfaced implants. Plast Reconstr Surg 1998; 6: 1922-31.

5. Luke JL, Kalinsky VF, Turnicky RP, et al. Pathological and biophysical findings associated with silicone breast implants: a study of capsular tissues from 86 cases. Plast Reconstr Surg 1997; 6: 1558-65.

6. Wallace MS, Wallace AM, Lee J, Dobke MK. Pain after breast surgery: a survey of 282 women. Pain 1996; 66: 195-205.

7. Mendes FH, Viterbo F, DeLucca L. The influence of external ultrasound on the histologic architecture of the organic capsule around smooth silicone implants: experimental study in rats. Aesth Plast Surg 2008; 32: 442-50.

8. Rzymski P, Skórzewska A, Skibinska-Zielinska M, Opala T. Factors influencing breast elasticity measured by the ultrasound Shear Wave elastography - preliminary results. Arch Med Sci 2011; 7: 127-33.

9. Rzymski P, Skórzewska A, Opala T. Changes in ultrasound shear wave elastography of normal breast during menstrual cycle. Clin Exp Obstet Gynecol 2011; 2: 137-42.

10. Moore JR. Applanation tonometry of breasts. Plast Reconstr Surg 1979; 63: 9-12.

11. Tebbetts JB. Dual plane breast augmentation: optimizing implant-soft-tissue relationship in a wide rabge of breast types. Plast Reconstr Surg 2001; 107: 1255-72.

12. White PF, Joshi GP, Carpenter RL, Fragen RJ. A comparison of oral of oral ketorolac and hydrocodone-acetaminophen for analgesia after ambulatory surgery: arthroscopy versus laparoscopic tubal ligation. Anesth Analg 1997; 85: 37-43.

13. Stavros AT (ed.). Breast ultrasound. Lippincott Williams \& Wilkins, Philadelphia 2004; 199-275.

14. Pacik PT, Nelson CE, Werner C. Pain control in augmentation mammoplasty using indwelling catheters in 687 consecutive patients: data analysis. Aesthetic Surg J 2008; 28: 631-41.

15. Jabs D, Richard BG, Richards FD. Quantitative effect of tumescent infiltration and bupivicaine injection in decreasing postoperative pain in submuscular breast augmentation. Aesthetic Surg J 2008; 28: 528-33.

16. von Sperling ML, Hoimyr H, Finnerup K, et al. Persistent pain and sensory changes following cosmetic breast augmentation. Eur J Pain 2011; 15: 328-32.

17. Romundstad L, Breivik H, Roald H, et al. Chronic pain and sensory changes after augmentation mammoplasty: long term effects of preincisional administration of methyloprednisolone. Pain 2006; 124: 92-9.

18. Kokot N, Gaca M. TIVA vs VIMA in day-case surgery procedures. Nowiny Lek 1999; 68: 178-90.
19. Rzymski P, Wilczak M, Opala T. Influence of sex hormones in women on breast elasticity measured by shearwave sonoelastography - a cross-sectional study. Gynecol Endocrinol 2011, May 25 - ahead of print.

20. Sharma P, Maffulli N. Biology of tendon injury: healing, modeling and remodeling. J Musculoskelet Neuronal Interact 2006; 2: 181-90.

21. Rzymski P, Kubasik M, Opala T. Use of shear wave sonoelastography in capsular contracture before and after secondary surgery - report of two cases. J Plast Reconstr Aesth Surg 2011, June 24 ahead of print. 